\title{
Los llamados "lugares sagrados": territorialidad, identidad y alteridad entre los tepehuanos del sur
}

\author{
So-called "Sacred Places": Territoriality, Identity \\ and Alterity among the Southern Tepehuan
}

\author{
Antonio Reyes Valdez \\ ESCUELA DE ANTROPOLOGÍA E HISTORIA DEL NORTE DE MÉXICO-INSTITUTO NACIONAL \\ DE ANTROPOLOGÍA E HISTORIA, odamareyes@gmail.com
}

Un tema común de unión entre los tepehuanos del sur de Durango (o'dam/audam), y de discusión entre éstos y diversas instancias del Estado mexicano, es el territorio y el control político del mismo. Adicionalmente, en años recientes la identificación y protección de los llamados "lugares sagrados" en las comunidades indígenas de México ha vuelto más compleja dicha relación al colocarse en el centro de la agenda de debate sobre el territorio. El presente artículo tiene como objetivo explicar cómo pueden entenderse desde la perspectiva del pueblo tepehuano del sur los llamados "lugares sagrados". Su comprensión se encuentra a su vez anclada en su construcción sociocultural del territorio, el cual tiene, como principales atributos, el ser "ancestral", "transformativo" y concebido desde distintos niveles de organización social. Consecuentemente, es posible hablar de distintas territorialidades tepehuanas, las cuales constituyen a su vez un elemento fundamental en los procesos de identidad/alteridad de este pueblo.

PALABRAS ClaVE: territorio, identidad-alteridad, lugares sagrados, historia agraria, tepehuanos.

A common topic of discussion between Southern Tepehuan people (O'dam/Audam) of Durango and diverse agencies of the Mexican State is territory and its political control. In recent years the identification and protection of the so-called "sacred places" of Mexican indigenous communities has taken center stage in this debate, making a difficult relationship even more complex. The aim of this paper is to explain how best to comprehend the notion of "sacred places" from a Tepehuan perspective. This understanding is stronglyrooted in the Southern Tepehuan socio-cultural construction of territory, whose principle characteristics include its "ancestral" and "transformative" nature, and the fact that it is conceived from various levels of social organization. Consequently, it is possible to speak of various "Tepehuan territorialities" that together constitute a fundamental feature of their identity/alterity processes.

KEYwORDS: territory, identity-alterity, sacred places, agrarian history, Tepehuan.

Fecha de recepción: 19 de junio de 2017 / Fecha de aceptación: 16 de mayo de 2018 / Fecha de versión definitiva: 28 de mayo de 2018 


\section{INTRODUCCIÓN ${ }^{\mathrm{I}}$}

18 de enero de 2015, los medios de comunicación locales en Durango reportaron que un grupo de tepehuanos ${ }^{2} \mathrm{de} \mathrm{Mez}-$ quital habían tomado las oficinas de la Secretaría de Agricultura, Ganadería, Desarrollo Rural, Pesca y Alimentación (sAGARPA) (Maldonado 2015), exigiendo la entrega de fondos federales del Programa de Apoyos Directos al Campo (Procampo) correspondientes a los años 2013 y 2014. El jefe estatal de la SAGARPA justificó la retención de recursos cuestionando la legalidad de la tenencia de la tierra en las comunidades indígenas de Durango. En entrevista radiofónica declaró que, "inclusive”, varias de esas comunidades "tenían títulos de la época colonial”. Aparte de demostrar su ignorancia sobre el proceso de Reforma Agraria Mexicana desarrollada en el siglo xx, y mediante el cual el Estado mexicano reconoció legalmente dichos territorios, este burócrata resaltó la fuente más significativa de conflicto entre el Estado mexicano y las comunidades tepehuanas: la tenencia de la tierra y la autonomía política de las mismas.

Adicionalmente, el reconocimiento y la defensa de los llamados "lugares sagrados" se han posicionado en años recientes en la agenda de discusión sobre el territorio de los pueblos indígenas del país (López Bárcenas 2015). Las diferentes concepciones sobre el territorio que sostienen los actores involucrados han derivado en el desarrollo de diversos peritajes antropológicos que permitan una

${ }^{1}$ El presente trabajo forma parte de los resultados del proyecto "Antropología e Historia de las Poblaciones Originarias de Durango", desarrollado por el Centro INAH Durango con Folio: 10182 a cargo del autor del presente artículo.

${ }^{2}$ Los tepehuanos del sur se llaman a sí mismos como o’dam (principalmente en municipio de Mezquital, Durango) y audam (principalmente en Pueblo Nuevo, Durango y Huajicori, Nayarit). Junto con los huicholes (wixaritari), los coras (nayeri), y los mexicaneros (nahuas), los tepehuanos del sur y sus respectivos territorios construyen la región histórico-cultural conocida como El Gran Nayar, la cual abarca porciones de los estados de Durango, Nayarit, Jalisco y Zacatecas. Se les llama "del sur" para diferenciarlos del grupo indígena homónimo que vive en el sur del estado de Chihuahua y a los cuales se refiere como tepehuanos del norte (ódami en su propia lengua) (Reyes Valdez 2006b, 5). 
MAPA I. Comunidades y variantes lingüísticas de los tepehuanes del sur
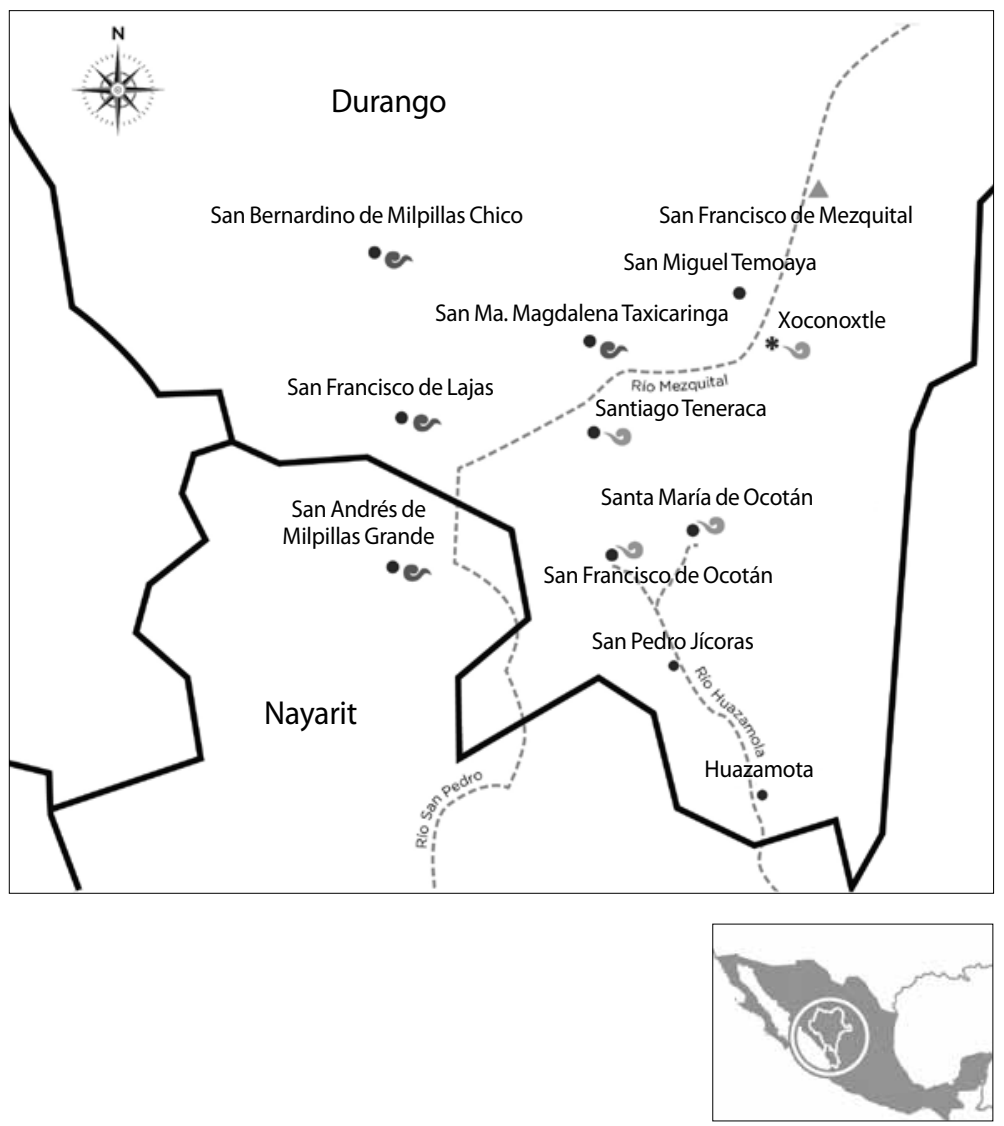

Simbología

\begin{tabular}{|c|c|}
\hline Estados & Pueblos tepehuanes \\
\hline Ríos & - Cabecera comunal \\
\hline Variantes dialectales del tepehuan del sur & A Cabecera municipal \\
\hline Pr Audam & * Localidad \\
\hline$\checkmark$ O'dam & \\
\hline
\end{tabular}

Fuente: Reyes 2006a. 
mayor comprensión entre ellas (Cfr. Comisión Nacional de los Derechos Humanos [CNDH] 2015). Los tepehuanos de Durango no escapan a esta discusión. El presente artículo tiene como objetivo explicar la importancia del territorio en los procesos de identidad/alteridad entre los tepehuanos del sur de Durango; cómo dicha relación se funda en la que establecen con sus ancestros y cómo ésta nos ayuda a comprender, desde la perspectiva tepehuana, eso que diversos agentes externos a este pueblo denominan como "lugares sagrados".

Con ese fin, en los siguientes apartados muestro cómo el término en espańol "lugares sagrados" es de uso reciente entre los tepehuanos, por lo que su comprensión mantiene un alto grado de ambigüedad; pero no sólo entre ellos, sino también entre los distintos agentes representantes de las instituciones estatales. En su versión más concreta, para los últimos, los "lugares sagrados" corresponden con un conjunto limitado de puntos en el paisaje susceptibles de ser contabilizados y señalados en un mapa y, en los cuales, los indígenas realizan rituales, entregan ofrendas o piden favores a los dioses ( $C f r$. Comisión Nacional para el Desarrollo de los Pueblos Indígenas [CDI] 2010, 43; Cfr. CNDH 2015). Comparado con la perspectiva indígena ésa no sería una idea falsa sino falaz, pues ésta corresponde sólo con una de las posibilidades dentro de la concepción tepehuana de lo que podría considerarse como "sagrado", y que siempre se relaciona con atributos propios de los ancestros. En ese sentido, y al considerar todo su territorio como ancestral, potencialmente todo su territorio tendría el carácter de "sagrado".

Para fines del presente texto, es necesario distinguir entre dos términos cercanos pero distintos. La "tierra", que es un concepto jurídico; y el "territorio" que tiene connotaciones políticas:

el territorio constituye el espacio que los pueblos indígenas necesitan para desarrollar su vida y mantenerse como tales; no lo pueden traspasar a terceros porque no es su propiedad, aunque pueden [ser] despojados por la fuerza, caso en que se generará un fuerte conflicto por la supervivencia; la tierra en cambio es un espacio de su propiedad, que sirve para establecer la 
vivienda o producir alimentos, se puede traspasar o adquirir por cualquier vía legal y los terceros no están legitimados para adquirirla violentamente. Finalmente, el territorio puede contener las tierras y éstas pueden formar parte de aquél, aunque en muchos casos no sucede así porque el territorio es más amplio que la tierra (López Bárcenas 2015, 87).

Adicionalmente, la "territorialidad" constituye el proceso de construcción, apropiación y control del territorio, mediante una amplia gama de prácticas agrícolas, rituales comerciales y políticas (Liffman 2012, 23).

Para desarrollar mi objetivo, primero presento una brevísima historia agraria de los tepehuanos en la que se muestra cómo, a lo largo del tiempo, los derechos legales sobre la tierra y el control del territorio han sido un tema de constante tensión con las diferentes versiones del Estado, desde la época colonial hasta nuestros días. En la tercera sección, explico el papel del territorio en ciertos procesos identitarios y de alteridad de los tepehuanos. En el siguiente apartado explico la noción tepehuana de xidhuukam, que regularmente traducen ellos mismos como "bendito", y que en todo caso sería lo más cercano a lo "sagrado". Al entender dicha noción y su relación con la base territorial de las comunidades agrarias, podremos aproximarnos a una posible idea tepehuana de "los lugares sagrados" y a la conformación de diversos territorios y territorialidades tepehuanas. En el sexto apartado termino con la exposición de lo que denomino "el carácter transformativo del territorio" que, a más de ser también una característica de los "lugares sagrados", es fuente constante de confusiones y desencuentros entre las comunidades tepehuanas y diversas instituciones del Estado.

\section{BREVE RECUENTO DE LA HISTORIA AGRARIA} DE LOS TEPEHUANOS

En la actualidad hay siete comunidades tepehuanas (en términos agrarios) reconocidas legalmente por el Estado mexicano (Reyes Valdez 2013, 378), y es en ese sentido que me refiero a ellas a lo largo del presente texto. Los límites legales actuales de las tierras de 
cada comunidad se sustentan en documentos coloniales reconocidos por el moderno Estado mexicano y su Reforma Agraria, mediante los procesos de Reconocimiento y Certificación de Bienes Comunales (Rствс) o vía el Decreto Presidencial (Sandoval et al. 1999, 111). Los tepehuanos reconocen el papel del Estado mexicano para preservar sus tierras ancestrales a pesar de las contradicciones que las nuevas regulaciones estatales pretenden imponer a través de la "certificación" y de los llamados Estatutos Comunales. La primera alienta a cada comunero a obtener un título de propiedad sobre su parcela, de la que actualmente sólo poseen el usufructo. Uno de los efectos más problemáticos de la certificación es que formaliza la división de la propiedad de las "tierras comunales", las que, en principio, pertenecen a todos los comuneros en conjunto.

Mediante los Estatutos Comunales se pretende establecer formalmente y por escrito, las reglas de operación de la propiedad comunal con la finalidad de dar certeza jurídica tanto a instituciones estatales como privadas ante cualquier proyecto o negociación que se quiera desarrollar con las comunidades. No obstante, el principal inconveniente para los comuneros radica en hacer permanentes y rígidas -al establecerse por escrito-, la toma de un sinnúmero de decisiones que normalmente se resuelven colectivamente mediante la asamblea. Estos dos temas muestran la faceta más reciente de un añejo problema entre las comunidades tepehuanas y las diferentes versiones del Estado con las que han tenido que negociar para preservar pleno derecho sobre sus tierras.

Lo anterior se refleja en las apariciones recientes y cada vez más frecuentes de los tepehuanos del sur en la prensa, exponiendo sus problemas relativos a la tenencia de la tierra, la autonomía política de las comunidades y su explotación por parte de la industria maderera (Cfr. Riley y Hobgood 1959; Cfr. Soto Soto 2015; Cfr. Moszowski et al. 2018). ${ }^{3}$ En el presente siglo destaca el conflicto protagonizado por los comuneros de Santa María de Ocotán y Xoconoxtle que estuvieron en los titulares de la prensa local y nacional

${ }^{3}$ En general, los tepehuanos del sur resaltan en las esferas regional y nacional por mantener un bajo perfil mediático. 


\section{MAPA 2. Comunidades tepehuanes y sus linderos}
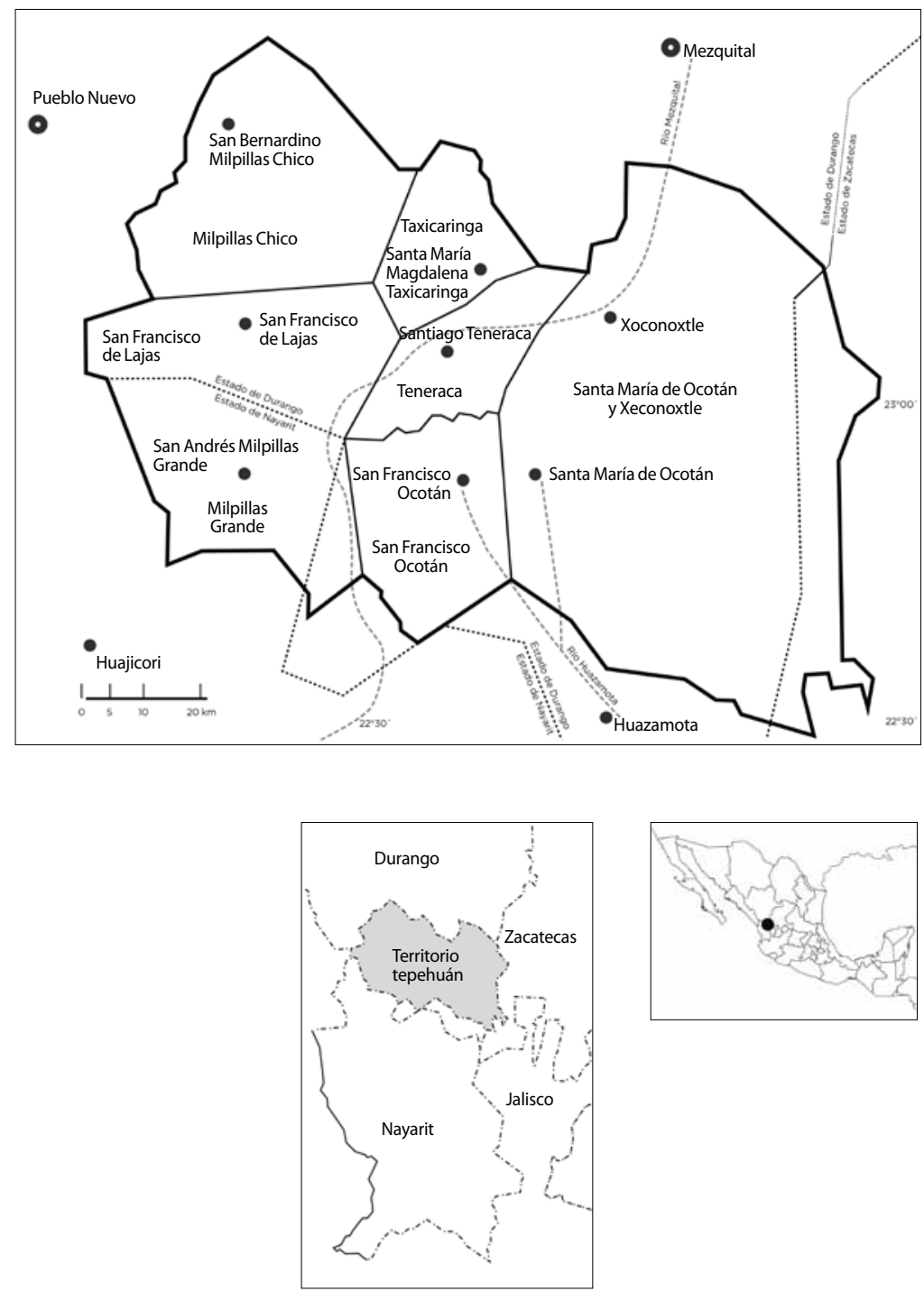

Fuente: Plan Lerma 1966. 
entre 2002 y 2004. Esta comunidad demandó la restitución de más de 5,000 hectáreas de tierra que obraban en posesión del ejido mestizo Bernalejo de la Sierra en el vecino estado de Zacatecas. Dicho conflicto escaló rápidamente de ser un problema entre dos núcleos agrarios a involucrar a los respectivos gobiernos estatales (Reyes Valdez 2006b, 15). Volveré sobre este particular líneas abajo.

La historia de este conflicto agrario -y otros similares- se remonta por lo menos al inicio del siglo XVII, cuando las comunidades tepehuanas aseguraron nuevos títulos de tenencia de la tierra mediante una Real Cédula que les otorgó la Corona española ( $C f$ r. Sánchez Olmedo 1980, 171-182). En 1705, el sacerdote a cargo de la misión franciscana de Mezquital, fray José de la Luz Urquiñola, solicitó a las autoridades coloniales el reconocimiento de las tierras de las comunidades tepehuanas en conjunto con la expedición de los documentos correspondientes de Santa María de Ocotán, San José Xoconoxtle, ${ }^{4}$ San Francisco de Ocotán, Santiago Teneraca y Santa María Magdalena Taxicaringa, ("Títulos Primordiales de Santa María de Ocotán" en Sánchez Olmedo 1980, 171-182). Junto con los tepehuanos, el sacerdote explicó que la Corona española originalmente otorgó los títulos en 1680, pero que se perdieron en un incendio de la iglesia en Santa María de Ocotán donde se encontraban resguardados. Ese mismo año (1705), el sacerdote y las autoridades de los pueblos antes mencionados, acompañados por representantes de la administración provincial de la Nueva Vizcaya, examinaron los límites y mojoneras entre las comunidades y estuvieron de acuerdo en la localización de las fronteras entre cada una. Con base en esa observación de campo, la administración colonial expidió los documentos correspondientes en 1712 (idem). Desde entonces, estos documentos (si bien los originales actualmente están perdidos) han sido la referencia para numerosos litigios de las comunidades tepehuanas.

${ }^{4}$ Frecuentemente denominado erróneamente en la documentación como San Andrés Xoconoxtle. Quiñones Martínez $(2013,251)$ atribuye el error al abogado Hernández y Marín que en 1888 representa a los habitantes de Santa María de Ocotán ante la Secretaría de Fomento. 
En el siglo XIx, como resultado de la Reforma Liberal de 1856, las compañías deslindadoras declararon que en el municipio de Mezquital había más de 2,000,000.00 hectáreas de tierras vacías y abandonadas (Calvillo 2004, 7; Quiñonez Martínez 2013, 246). Tres décadas más tarde, en 1885, durante la administración del presidente Porfirio Díaz, la compañía privada de "Rafael García Martínez y Asociados" contrató al ingeniero Manuel E. Caravantes para volver a evaluar dichas tierras. El resultado fue un mapa conocido como el Plan Caravantes, en el cual el ingeniero dio reconocimiento de 421,000 hectáreas pertenecientes a la comunidad de Santa María de Ocotán (Martínez Guzmán 2004, 23).

En 1889, los comuneros de Santa María de Ocotán contrataron al abogado Juan Hernández y Marín para defenderlos de los múltiples intentos por agentes externos para despojarlos de sus tierras. ${ }^{5}$ Basado en el Plan Caravantes, Hernández y Marín hizo sus propias medidas obteniendo el reconocimiento para la comunidad de un total de 421,139 hectáreas por parte de la Secretaría de Agricultura y Fomento (Calvillo 2004, 8; Quińonez Martínez 2013, 252). Más tarde, Hernández y Marín solicitó que el estado de Durango le pagara sus servicios por la suma de 14,049 pesos (de aquella época), lo que le fue cubierto con una compensación de 120,000 hectáreas de las tierras de la misma comunidad indígena (Calvillo 2004, 9; Quiñonez Martínez 2013, 252).

En 1918 y 1919, durante el periodo de la Revolución Mexicana y después de la formulación de la Constitución de 1917, los habitantes de San José Xoconoxtle y Santa María de Ocotán solicitaron el reconocimiento de su territorio con base en la documentación emitida por las autoridades coloniales en 1712. A pesar de que en esos años las autoridades indígenas enviaron mapas, planos y títulos coloniales, la Comisión Nacional Agraria negó el reconocimiento de dicho reclamo y no fue atendido sino hasta 1933 (Morris 2015, 329). En ese momento, el entonces gobernador de Durango, Carlos Real, ordenó a un grupo de agrónomos que condujeran un estudio

${ }^{5}$ Calvillo (2004, inédito), quien realizó un profundo recuento de este proceso agrario, observa que Hernández y Marín tuvo acceso a esta serie de documentos compilados entre 1828 y 1836 en la administración del estado de Durango. 
topográfico con la finalidad de regresar las tierras que reclamaban las comunidades de San José Xoconoxtle y Santa María de Ocotán. Estos trabajos reavivaron la controversia sobre la propiedad de más de 120,000 hectáreas, del espacio conocido como "Predio de la Montaña" y que el abogado Hernández y Marín había tomado de la comunidad en 1899 (Quińones Martínez 2013, 252-253). En 1928, el estado de Durango tomó el control sobre esta porción de tierra, ordenando a los agrónomos atender los reclamos de San José Xoconoxtle y Santa María de Ocotán, mientras que el gobernador Real vendió el "Predio de la Montaña" al empresario Esteban Rosas, con una superficie de 177,105 hectáreas (Calvillo 2004, 10; Morris 2015, 329).

Finalmente, en 1936 y después de más de 15 años de dificultades legales (muchos años antes que las otras comunidades tepehuanas), los comuneros de San José Xoconoxtle y Santa María de Ocotán obtuvieron el reconocimiento y titulación de sus tierras comunales por parte del gobierno postrevolucionario, quizás como recompensa por su lealtad al gobierno mexicano durante la segunda Guerra Cristera ( $C f$ r. Morris 2015, 368). El reconocimiento fue por una superficie de 421,139 hectáreas, que no pudo ser ejecutada sino hasta 1975 y por una superficie de 300,140 hectáreas, ya que en ella se refería a los puntos y mojoneras mencionadas en el Plano Caravantes de 1885 , sobre los cuales no se tenía plena identificación (Quiñones Martínez 2013, 255).

Adicionalmente, y como resultado de esta negociación, el nuevo título unió a las dos comunidades dando origen a la actual comunidad agraria de Santa María de Ocotán y Xoconoxtle con un único cuerpo de autoridades en ese ámbito (el Comisariado de Bienes Comunales), decisión que aun hoy muchos de los habitantes de Xoconoxtle buscan revertir (Reyes Valdez 2006a, 39).

Posteriormente, otras comunidades siguieron los procesos legales de Reconocimiento y Titulación de Bienes Comunales (RTBC): San Miguel Temoaya en 1943; Santa María Magdalena de Taxicaringa en 1951; San Bernardino de Milpillas Chico en 1961; San Francisco de Lajas en 1965; San Francisco de Ocotán en 1976; y Santiago Teneraca en 1987 (Rosa 2003, 66-67). 
A lo largo del tiempo, los límites territoriales señalados en los nuevos títulos agrarios han sido causa de múltiples conflictos entre las comunidades tepehuanas, o entre ellos y los vecinos de comunidades mestizas y propiedades privadas. Tal vez el más conocido sea con respecto a las fronteras septentrional y oriental de Santa María de Ocotán y Xoconoxtle ya mencionado líneas arriba. En 1957, la oficina federal de asuntos agrarios detectó una invasión al norte de dicha frontera por una propiedad privada conocida como "El Predio las Margaritas" en Durango, mientras que la frontera oriental estaba siendo invadida por el ejido zacatecano de Bernalejo de la Sierra (Calvillo 2004, 23-39). El conflicto fue largo y complicado debido a los constantes argumentos y contraargumentos por las partes involucradas. En 1997, el presidente Ernesto Zedillo decretó que el ejido Bernalejo regresara 5,456 hectáreas a Santa María de Ocotán y Xoconoxtle. Sin embargo, los habitantes del primero no acataron la orden presidencial y el conflicto alcanzó su punto más violento a inicio del año 2000, cuando lo tepehuanos de Santa María de Ocotán ocuparon las tierras que se encontraban en disputa. Ambas poblaciones estuvieron al borde de la confrontación armada y el conflicto devino en un problema entre los estados de Durango y Zacatecas. Entre 2002 y 2004, hubo muchas negociaciones que involucraron a varias oficinas de los distintos niveles gobierno, lo que provocó que en 2004 el gobierno federal expulsara a la gente de Bernalejo y la indemnizara por las tierras devueltas a los tepehuanos (Reyes Valdez 2006b, 15).

Éste es el caso sin duda más conocido entre muchos. No obstante, ha habido conflictos similares sin recibir el mismo nivel de cobertura periodística. Por ejemplo, el que se mantiene entre Santa María de Ocotán y Santiago Teneraca en un lugar conocido como Unam cha’m o Las Ramadas, en el cual habitan miembros de ambas comunidades, conservando cada uno su propio lado del poblado; entre Santiago Teneraca y Santa María Magdalena Taxicaringa en el área de Tierras Coloradas; entre San Francisco de Ocotán y San Pedro Jícoras; y entre San Bernardino Milpillas Chico y la propiedad privada del Predio de Cuevecillas. Notoriamente, los conflictos por linderos se incrementaron a partir de la década de 1960 a causa de la titula- 
ción de los núcleos agrarios y el desarrollo de la industria forestal con la consecuente "monetización" del bosque (Moszowski et al. 2018).

\section{EL TERRITORIO, IDENTIDAD Y ALTERIDAD ENTRE LOS TEPEHUANOS}

Las comunidades tepehuanas tienen una base territorial en aquellas tierras que ellos mismos identifican como ancestrales y que la reforma agraria mexicana validó legalmente mediante los procesos de Reconocimiento y Titulación de Bienes Comunales (Sandoval et al. 1999, 111). Los territorios comunales constituyen los espacios en los que los tepehuanos desarrollan y organizan su vida social, sancionados por tres sistemas de autoridades con un carácter igualmente comunitario y con una jurisdicción concomitante: los jefes del xiotalh o mitote comunitario, de raigambre aborigen y con un probable origen prehispánico; ${ }^{6}$ las autoridades de los llamados "gobiernos tradicionales" con un origen colonial; y las autoridades agrarias emanadas de la reforma del mismo tipo en el siglo xx (Reyes Valdez 2009). Además de su papel como representantes de sus comunidades ante diversas instancias del Estado -en el caso de las dos últimas-, los tres conjuntos constituyen diferentes instancias de intermediación con distintos tipos de ancestros: los dioses de la caza y la agricultura (aborígenes) en el primer caso; los dioses cristianos (de origen europeo) en el segundo; y el trato con los ancestros "más delicados" de los mestizos que tienen que ver con el Estado y la regulación de la tenencia de la tierra (Reyes Valdez 2015). ${ }^{7}$

${ }^{6}$ Los xiotalh o mitotes, como también se les denomina, son ceremonias de carácter agrícola y de cacería que se realizan estacionalmente (transición lluvias-secas-lluvias) en espacios ceremoniales al aire libre conocidos como patios de mitote. Estas ceremonias se organizan tanto en un nivel comunitario (de la comunidad agraria) y de parentesco (incluye a miembros identificados con un mismo apellido paterno) (Reyes Valdez 2006a).

${ }^{7} \mathrm{La}$ antropología amazonista ha desarrollado modelos interpretativos en los que la identificación con "el otro" conlleva una coincidencia en las categorías de "ancestro" y "enemigo" en un proceso que algunos autores denominan "alteridad constituyente" (Erikson 1986), y cuyas nociones han sido exitosamente exploradas en México por autores como Pitarch (2000) en el área maya y Neurath (2008) para el caso huichol. 
Los grupos de parentesco y los niveles comunitarios de organización son mutuamente constituyentes: en su forma más elemental, los ranchos corresponden con unidades domésticas integradas por un grupo de parentesco; éstos en conjunto conforman a su vez unidades más grandes (poblados y anexos) que asimismo integran la comunidad agraria (Cfr. Mendía Soto 2016, 46-67). Simultáneamente, el desarrollo de estas unidades de organización social se da física y espacialmente en el marco del territorio comunitario, por lo que no es posible establecer cuál de los dos niveles precede al otro. Así, los territorios comunales delimitados por sus respectivos linderos cobran gran importancia en el desarrollo de las relaciones sociales, pues son la base territorial de las relaciones de parentesco y comunales, que controlan y administran espacios de producción (milpas y coamiles), centros ceremoniales (patios de mitote familiar) y lugares de culto (santuarios y moradas de los ancestros).

En el nivel del parentesco, los grupos de filiación tienen una base territorial en sus ranchos; se identifican tanto con el apellido paterno que los congrega como con los ancestros a los cuales rinden culto en los patios de mitote familiar. En el nivel comunitario, la identificación se establece a partir de los nombres de las comunidades, sus límites territoriales y sus gentilicios. Los primeros son homónimos con los de sus pueblos cabecera o "cabeceras comunales", los cuales aluden al nombre de un santo patrón. Adicionalmente, esos lugares también tienen un topónimo en lengua indígena al que se atribuye gran antigüedad y a partir de los cuales se forman los gentilicios con los que los tepehuanos se identifican como miembros de alguna comunidad en oposición a los miembros de otras, estableciendo una forma primaria de identidad/alteridad. Este nivel de identificación tiene mayor trascendencia en la vida cotidiana de los tepehuanos que, por ejemplo, la posible identidad étnica. La historia reciente de los tepehuanos nos muestra múltiples movimientos de reivindicación comunitaria a partir de los litigios agrarios. En cambio, no se ha presentado ningún movimiento de reivindicación étnica que congregue a las comunidades tepehuanas en su conjunto. Así, resulta más relevante ser jukterik de Juktir (comunidad de Santa María de Ocotán); chianarak de Chianarkam (Santiago Teneraca); 
koxbhilik de Koxbilhim (San Francisco de Ocotán), o mua'lhakam de Mua'lham (San Bernardino de Milpillas), etcétera, que ser tepehuano, ya sea o'dam o audam. ${ }^{8}$

El caso de los habitantes de San Pedro Jícoras arroja luz sobre este importante aspecto de la relación entre el territorio y los procesos de identidad/alteridad. San Pedro Jícoras es bien conocido en la literatura por ser el hogar de la población más septentrional de habla náhuatl (Valiñas 1991, Jáuregui y Magriñá 2002, Alvarado Solís 2004). No obstante, además del español, gran parte de su población también habla o solamente habla tepehuano, mientras que otra parte es incluso trilingüe. A esta versión del náhuatl reconocida en la literatura como mexicanero la reconocen muchos de sus hablantes como sanpereñ -muchos incluso desconocen el término de "náhuatl"-. Tanto los habitantes de este lugar como sus vecinos identifican a sus habitantes también como sanpereñ, gentilicio del topónimo San Pedro o sanpegro, sin importar la lengua que hablan. Es decir, en este caso al igual que en los casos tepehuanos, el gentilicio, el idioma y la gente de San Pedro Jícoras son designados a partir del nombre de la comunidad, su cabecera comunal homónima y, en este caso, el santo patrón que les da nombre. Los procesos identitarios con base en los límites comunales y su respectivo gentilicio son concomitantes con los procesos opuestos de alteridad: si soy chianarack (de Chianarkam o Santiago Teneraca) no soy jukterik (de Juktir) ni sanpereñ (de San pedro Jícoras), etcétera.

Un atributo del territorio vinculado con lo anterior, y que con frecuencia se introduce en las disputas por el mismo, es el de ser "ancestral". Los nombres compuestos de las comunidades en español-náhuatl, mencionados arriba -por ejemplo, Santa María de Ocotán- aluden a un ancestro o santo patrón cristiano, mientras que el topónimo ódam con frecuencia alude a eventos mitológicos o muy antiguos (Reyes Valdez y García Salido 2017). Muchos de los

${ }^{8}$ Aunque Juktir, Chianarkam, etcétera, son los topónimos indígenas de las cabeceras comunales, los tepehuanos también lo usan por extensión para referirse a la totalidad de sus respectivas comunidades de modo similar a como usan los nombres correspondientes en espańol Santa María de Ocotán y Santiago Teneraca que nombran tanto al pueblo cabecera como a toda la comunidad. 
lugares sobre los cuales se encuentran las mojoneras y a partir de las cuales se proyectan las líneas que definen los territorios comunales tienen dicho carácter. En la mayoría de los casos se trata de elevaciones o topoformas sobresalientes en el paisaje, muchos de ellos correspondientes con lo que tentativamente podríamos definir como "lugares sagrados", según veremos en el siguiente apartado.

Los límites territoriales entre comunidades (muy a menudo disputados desde la visión de cada una) también tienen el carácter de ancestral porque fueron trazados por los antepasados, están registrados en documentos antiguos (los títulos primordiales) y contienen dentro de su perímetro otros sitios ancestrales medulares en las actividades rituales de los grupos de parentesco patrilineales que, tomados en conjunto, constituyen a cada comunidad. Así, los documentos, pero sobre todo los de origen colonial, adquieren de manera concomitante un carácter "delicado", y por esta razón, son objeto de cuidado y un trato especial por parte de los responsables de su resguardo. Como ha observado Ethelia Ruiz Medrano $(2010,211)$ para otros casos mexicanos, este tipo de documentos, en conjunto con las historias locales, constituyen un tipo de mitología contemporánea que permite a las poblaciones indígenas entablar negociaciones y reclamos legales de diversa índole. Así, recuerdo y se explica cuando en ocasión de la celebración de un mitote comunitario en Santiago Teneraca, verificado días antes de atender un asunto legal de carácter agrario, los títulos comunales certificados descansaban sobre el altar del centro ceremonial durante las oraciones de los jefes del mitote, los cuales, traían a sus plegarias los sitios consignados ahí.

\section{LOS LlAMADOS “LUGARES SAGRADOS”}

En contraste con las acciones tomadas por muchos de los movimientos indígenas latinoamericanos por el "derecho de la tierra", los llamados "lugares sagrados" no formaban parte de la agenda en las relaciones entre los tepehuanos y las instituciones del Estado mexicano (por ejemplo, la Secretaría de la Reforma Agraria). No fue sino hasta después de dos asuntos relacionados con el territorio huichol que este tema tomó gran importancia en la región. Primero, en 2008, 
la construcción de una carretera entre Huejuquilla y Bolaños en Jalisco destruyó el monumento monolítico conocido como el Paso del Oso, causando mucha molestia entre los huicholes (Neurath 2015); segundo y más reciente, el movimiento y gran controversia que surgieron tras la autorización por parte del gobierno federal de un proyecto minero en Wirikuta (Liffman 2015, Neurath 2015). Como consecuencia, las instituciones mexicanas presentaron un inusitado interés por los lugares sagrados indígenas que se manifestó sobre todo en la solicitud de peritajes, consultas (Cfr. CDI 2010; $C f$ r. CNDH 2015), listados y censos de este tipo de lugares a diversos especialistas, a través de la Comisión Nacional para el Desarrollo de los Pueblos Indígenas (CDI) que fungió como intermediaria. ${ }^{9}$

No fue sino hasta hace poco tiempo que los tepehuanos empezaron a utilizar el término "sagrado", aparentemente como consecuencia de estas circunstancias. Es difícil conocer cuál es la noción al respecto con la que los representantes de las instituciones estatales operan sobre el terreno. No obstante, de acuerdo con diversas legislaciones estatales ${ }^{10} \mathrm{y}$ el resultado plasmado en los llamados Estatutos Comunales de Santa María de Ocotán y Xoconoxtle (que circula en forma de manuscrito), la visión que prevalece se aproxima a la que enuncia el "Informe final de la Consulta sobre Lugares Sagrados del Pueblo Wixarika" (CDI 2010), en el que mencionan "son lugares donde se cumplen las mandas [...] son espacios donde los Wixaritari piden y agradecen [...] en los lugares sagrados se pide por el bienestar de todas las personas del mundo" (CDI 2010, 43). ${ }^{11}$ Esta noción se aproxima a la que enunciaba en la introducción del presente texto como: un conjunto limitado de puntos en el paisaje susceptibles de ser contabilizados y seńalados en un mapa y, en los cuales, los indígenas realizan rituales, entregan ofrendas o piden favores a los dioses.

${ }^{9}$ Personalmente recibí varias llamadas telefónicas tanto de la delegación estatal en Durango como de algunas instancias de las oficinas centrales de la CDI, solicitándome un listado de "lugares sagrados" de los tepehuanos del sur.

${ }^{10}$ Por ejemplo, en la Ley del Patrimonio Cultural del Estado de Jalisco (CDI 2010, 26).

${ }^{11}$ Igualmente, pude advertir dicha visión a partir del trato que tuve (entre los años 2012 y 2015) con trabajadores de diferentes niveles de la CDI y del Tribunal Agrario en Durango. 
¿Pero cómo puede ser entendida dicha noción desde el punto de vista indígena? El término o’dam (idioma tepehuán del sureste) que comúnmente usan los tepehuanos para referirse a aquellos contextos que podríamos identificar como "sagrados" es xidhuukam, el cual ellos mismos traducen al español como "bendito". La cualidad de xidhunkam se adquiere como resultado de una relación con los ancestros deificados o dioses, que son los únicos seres que "en esencia" se les atribuye el carácter de xidhunkam. Es decir, los dioses son per se xidhuukam. Pero incluso éstos fueron "gente común" en un pasado remoto, "ancestros", que lograron deificarse a sí mismos mediante la práctica del autosacrificio, lo que los tepehuanos denominan como "ponerse benditos" o ponerse xidhuukam (Reyes Valdez 2015, 59). Asimismo, las cosas, las personas y los lugares pueden adquirir la condición de xidhuukam en función del contacto con los ancestros y, en consecuencia, también serán objeto de recibir un trato o conducta específica por parte de las demás personas. En el caso de la gente, "ponerse bendito" siempre comienza con un baño para inmediatamente empezar a guardar las abstinencias prescritas que consisten en no tomar alcohol, no enojarse, ni tener contacto físico alguno con el sexo opuesto -especialmente relaciones sexuales-. Algunos contextos de contacto con los dioses también demandan el ayuno o comer cierto tipo de alimentos en cantidades limitadas (Reyes Valdez 2006a, 49). Fue a través de estas prácticas que los ancestros se divinizaron y fueron al cielo (Reyes Valdez 2015, 248).

En el caso de algunos objetos, el contacto con los ancestros también los vuelve xidhuukam, si es que ellos mismo no lo son también por provenir de un pasado remoto. Por ejemplo, las iglesias edificadas son xidhuukam dado que las deidades cristianas habitan en ellas; todos los objetos como la ropa, las velas y las flores que se usan en las ceremonias también se consideran xidhuukam ya que han estado en contacto con los dioses. Las personas que participan en estas ceremonias o los que van a la iglesia deben guardar las abstinencias prescritas para estar xidhuukam temporalmente y poder aproximarse a las deidades. Terminada la relación, deben guardar dicho estado por un periodo equivalente al de las ceremonias para separarse gradualmente de las deidades. 
En el caso del territorio, éste es "ancestral" porque precede a la existencia humana y fue creado y habitado por los antepasados o por formas ancestrales de humanidad anteriores a la actual (Reyes Valdez 2015, 247-267). Pero si bien algunos de los ancestros creadores se transformaron a sí mismos en dioses a través de mantener las abstinencias rituales necesarias, no todos consiguieron dicha condición. La mitología tepehuana establece que, por lo menos, hubo tres humanidades previas a la actual y que fueron subsecuentemente destruidas en un pasado remoto. ${ }^{12}$ Una narración menciona que al final de celebración del primer xiotalh ciertos seres se petrificaron en el momento del primer amanecer. El territorio está lleno de lugares que dan testimonio de dicho evento, principalmente con monolitos en forma de personas, animales u objetos de ese tiempo (Reyes Valdez 2015, 134). Asimismo, durante esta ceremonia los tepehuanos también controlaron y mataron al demonio telúrico relacionado con la Madre Tierra conocido como Chu'ulh. En ocasiones, la mitología retrata a Chu'ulh como una anciana que comía nińos y con la capacidad de transformarse en una mujer joven para seducir hombres infieles. Los relatos cuentan que los o'dam sólo se pudieron deshacer de Chu'ulh cuando la engañaron durante el xiotalh, emborrachándola con una bebida preparada con escorpiones, arañas y víboras. Una vez que cayó rendida, la sepultaron con el fuego sagrado de la ceremonia. Chu'ulh explotó y su cuerpo se esparció por el paisaje. Su hígado se convirtió en piedras, sus costillas se encuentran calcadas en las laderas de los cerros, y su cerebro brota en la raíz de un árbol (un tipo de ficus) cuyas raíces sobresalen el nivel del suelo (Hobgood, 1970, Reyes Valdez 2018, 30). La destrucción de Chu'ulh y su transformación en diversos rasgos del paisaje dota de sentido a la observación de Lumholtz (1986 [1902], 115) a finales del siglo xIx, cuando se mofaba del trabajo de los misioneros con los huicholes al afirmar que si querían erradicar la idolatría tendrían que llevarse todas las piedras.

${ }^{12}$ Como observan Descola $(2012,36)$ y Viveiros de Castro $(2013,432)$ en la amazonia, la "humanidad" debe entenderse aquí como "condición social de la persona" y no por sus características biológicas que, en el caso o’dam, estaría definida principalmente por el conocimiento del cultivo y el uso del maíz como alimento (Reyes Valdez 2015, 247). 
Otra humanidad tepehuana "ancestral", previa a la actual, corresponde a los gigantes. La evidencia material de su existencia incluye objetos o herramientas enormes (piezas arqueológicas) encontradas en cuevas a lo largo del territorio habitado por los tepehuanos, tales como ollas, metates y manos de metate. Estos seres tenían maíz, así como el conocimiento y las herramientas para cocinarlo; pero no podían ingerirlo porque no tenían ano y no podían defecar. "Solo hacían como que se lo comían", y cuando realmente lo hicieron "orinaban puro pixnate (maíz tostado mezclado con agua)". Estos humanos pre-o'dam desaparecieron "cuando vino el viento amargoso" y los devastó. Algunos de ellos trataron de refugiarse en cuevas, pero finalmente perecieron (Reyes Valdez 2015, 249). ${ }^{13}$

La humanidad actual es el resultado de una devastación causada por el diluvio universal. ${ }^{14}$ El relato trata de un hombre solitario que logró salvarse flotando en un bule junto con su perrita negra, semillas de maíz, semillas de ciruelo y otros animales. Después de 40 días de flotar en el océano y encender una fogata en su bote, la tierra se secó y el hombre fue capaz de dejar el bule para poblar la tierra de nuevo. ${ }^{15} \mathrm{~A}$ pesar de su soledad, cada tarde después de trabajar en el campo el hombre regresaba a su casa y encontraba hechas las tortillas. Él se preguntaba quién las podría haber hecho, ya que vivía él solo con su perrita y otros animales. Un día fingió salir de casa y se escondió. Así, observó como la perrita se quitaba la piel "como si fuera una chamarra", emergiendo una mujer con un vestido blanco. El hombre rápidamente tomó la piel del perro y la arrojó al fuego, con lo que la mujer permaneció como tal. El hombre y la mujer tu-

${ }^{13}$ Este relato comparte muchos elementos con la "historia de los soles" mesoamericana. En la versión mexica los gigantes vivieron bajo un segundo sol y fueron destruidos cuando el cielo colapso, mientras que el cuarto sol fue destruido por el viento (Brotherston 1992, 238-245). En la mitología cora los gigantes se alimentaban con piedras, incienso y carne cruda, y murieron por el efecto de un humo venenoso. (Valdovinos 2008, 31).

${ }^{14}$ En la leyenda mexica de los soles, el diluvio había destruido el primer sol -el solagua- y convirtió a los humanos en peces (Brotherston 1992, 241).

${ }^{15}$ Según la versión que me narró don Trinidad Solís de Santa María de Ocotán. Otras versiones consignan que pasaron cinco ańos flotando en el mar (Ambriz y Gurrola 2013, 30-35; Willett 1991, 271). 
vieron hijos, razón por la cual los o'dam dicen que son descendientes de la perrita (Reyes Valdez 2015, 249; Cfr. Willett 1991, 276).

Bajo estas condiciones, los territorios comunales tepehuanos son ancestrales en su totalidad. No obstante, cabe señalar que hay lugares específicos en dicho territorio culturalmente más relevantes que otros, en particular, a los que se atribuye el carácter de xidhuukam. Éstos son la morada de los ancestros deificados, "los dioses", o bien, lugares que dan cuenta de sus acciones en un pasado muy remoto. Dada su condición, se les considera como "delicados" y su aproximación demanda una actitud de mucho respecto y el que las personas adquieran también el estatus de xidhuukam mediante la observación de las abstinencias prescritas so pena de enfermar o morir. Éstos son el tipo de lugar que más se aproxima a lo que en español y de manera generalizada se denominan como "lugares sagrados". Se trata de sitios concretos, muy numerosos y prácticamente incontables con nombres tales como Susban tam, Lugar de Sapos; Ontolhim, Lugar donde pasó la Sal; Chianarkam, Lugar de Oraciones; o Bodam tam, Lugar del Hombre Acostado (o muerto) (Reyes Valdez y García Salido 2017). Otros sitios, como los patios ceremoniales de tipo mitote, las iglesias o santuarios en cuevas que también son moradas de los dioses donde los tepehuanos les rinden culto.

En algunos casos, la condición xidhuukam de estos sitios está determinada por ser el lugar en el que se consigna la aparición de alguna de las deidades cristianas. Los casos más claros los representan los cerros patronales de las cabeceras comunales. A cada comunidad, y en particular a la cabecera comunal homónima, corresponde un santo patrón tutelar que da su nombre al centro político. Así, el nombre español-náhuatl que se atribuye a Juktir o Santa María de Ocotán, honra a la virgen María en su advocación de la Inmaculada Concepción; ${ }^{16}$ Chianarkam ${ }^{17}$ o Santiago Teneraca honra a Santo Santiago; Kauxbilhim, San Francisco de Ocotán, honra a san Francisco, y así

${ }^{16}$ La palabra "Ocotán” por otro lado significa "el lugar del pino” en náhuatl: Ocotlán, mientras que para Juktir se propone el significado "entre pinos" (Reyes Valdez y García Salido 2017, 342).

${ }^{17}$ De etimología poco clara. Reyes Valdez y García Salido (2017) proponen el significado de "lugar de bendiciones" o "lugar de oraciones". 
en todos los casos. En cada comunidad hay también un relato acerca del lugar de la primera aparición de su santo patrón, ya sea en la cima de un cerro o un peñasco en las inmediaciones del pueblo cabecera (Cfr. Rosa 2003, 6; Cfr. Rangel Guzmán 2012, 173-256).

Por ejemplo, en Santa María de Ocotán los relatos informan que un niño encontró a la Virgen cerca del pueblo en la parte alta de Naksir tam (Cerro del Alacrán). La gente decidió llevarla al pueblo al pie del cerro. Sin embargo, a la mañana siguiente, la virgen había desaparecido y las personas la encontraron nuevamente en el lugar de su aparición. De nueva cuenta la llevaron al pueblo, pero ella insistió en regresar a la cima del cerro. Este patrón se repitió cinco veces hasta que los ódam construyeron una iglesia donde la colocaron. De acuerdo con el relato, finalmente la virgen se sintió cómoda con su nueva casa y decidió permanecer ahí (Rosa 2003, 6). ${ }^{18}$ Actualmente, la cima de Naksir tam alberga dos capillas señalando el lugar original de la aparición de la Virgen (Reyes Valdez 2006a, 44).

Con base en lo expuesto en este apartado, podemos confirmar con mayor seguridad lo que apenas sugería al final de la sección anterior, "que muchos de los lugares sobre los que se encuentran las mojoneras de las comunidades son, en sí mismos, "lugares sagrados", mejor dicho, xidhuukam. Permítaseme desarrollar este punto en el apartado siguiente. Adicionalmente, podemos observar el contraste entre la amplia gama de posibilidades a que da lugar la noción de xidhuukam que nos permite identificar "lugares ancestrales", en contraste con la muy limitada -y ambigua- noción de "lugares sagrados" enunciada líneas arriba, por lo que resultaría un error el simplemente sustituir o traducir el término "lugares sagrados" por el de "lugares xidhuukam", toda vez que no son plenamente correspondientes el uno con el otro.

${ }^{18}$ En San Francisco de Ocotán pasó lo opuesto: se dice que san Francisco apareció exactamente donde actualmente se encuentra la iglesia. Los lugareńos llevaron a san Francisco a un lugar cercano llamado La Mesa, pero el santo regresaba al sitio de su aparición. Finalmente, la gente estuvo de acuerdo en construir una iglesia en ese lugar (Cruz 2007, 44; Cfr. Rangel Guzmán 2012, 210). Asimismo, Rangel Guzmán (2012) documenta como estos relatos son comunes a indígenas y mestizos de la región del sur Durango y norte de Nayarit. 


\section{LOS TERRITORIOS TEPEHUANOS}

En la región del Gran Nayar, y entre otras poblaciones indígenas, los huicholes resaltan por el reconocimiento explícito de un amplio territorio marcado por puntos que son destino de peregrinaciones por parte de todas sus comunidades y grupos de parentesco, tales como: Wirikuta, Hauxamanaka, Tatei Xapawiyeme, Haramara y Teakata (Jáuregui et al. 2003). Los coras y sus autoridades comunales hacen algo similar colectando agua de los sitios sagrados para marcar los límites de su territorio (Coyle 2001, 42). ${ }^{19}$

Los tepehuanos contrastan en la región del Gran Nayar con coras y huicholes, porque no realizan grandes peregrinaciones organizadas multitudinariamente a lugares alejados de sus comunidades. Pero ello no significa que no reconozcan un territorio allende sus límites comunales. Tómese como ejemplo Chametla, el Lugar de los Muertos, en la costa del Pacífico al sureste de Sinaloa, al que todas las almas tepehuanas llegarán tras seguir un camino que atraviesa la Sierra Madre Occidental en un trayecto de oriente a poniente (Rangel Guzmán 2008 y 2012, 213-222; Reyes Valdez et al. 2015). El Lugar del Bule (del mitote) en el poblado mestizo de Boca del Mezquital (Reyes Valdez 2006a, 46) o el del Arco en la Sierra de Órganos en Zacatecas (Hobbgood 1970, 403; Reyes Valdez 2006a, 46). Incluso, Real de Catorce, en el desierto potosino, es reconocido por los tepehuanos como un lugar de gran importancia. Todos estos lugares pueden ser calificados como xidhuukam toda vez que son lugares ancestrales -relacionados con un ancestro deificado o sus acciones- cuya aproximación por parte de la gente demanda mantener abstinencias rituales. Sin restarles importancia en la cosmovisión tepehuana, ninguno de ellos suscita ciclos de peregrinación comunitarios o multitudinarios.

En cambio, y en ese tenor, los tepehuanos conceden mayor importancia a lugares xidhuukam que se encuentran dentro de los límites de cada comunidad. Como expliqué en el apartado anterior,

${ }^{19}$ Los distintos grupos de filiación difieren de los lugares específicos en los que colectan el agua de los manantiales, aunque coinciden en que siempre se trata de una montaña ligada con algún ancestro (Coyle 2001, 41). 
la autoidentificación comunal se construye por el desarrollo de la vida de los grupos de parentesco y los comuneros en las tierras comunales. En ello, las actividades rituales tienen un papel preponderante, toda vez que mediante ellas se refrendan relaciones con los ancestros de los niveles de organización social (Reyes Valdez 2015). ${ }^{20}$

$\mathrm{Si}$ bien los tepehuanos en general reconocen y comparten lugares xidhuukam más allá de sus tierras comunales, cada comunidad, e incluso, cada grupo de parentesco reconoce un conjunto de lugares xidhuukam como propios, toda vez que aluden o se vinculan con sus ancestros particulares. Ello permite de manera recíproca a cada grupo parental y a los miembros de cada comunidad tepehuana distinguirse unos de otros. Consecuentemente, es posible identificar múltiples territorios y en consecuencia múltiples "territorialidades tepehuanas" basadas en el reconocimiento de ciertos lugares que resultan relevantes al menos en tres niveles: parental, comunal y étnico. De esta forma, aun cuando hay lugares relevantes y comunes para todas las comunidades tepehuanas, su importancia es secundaria para los otros dos niveles puesto que no forman, necesariamente, parte de un culto o de una interacción en estos niveles de organización social.

Como ejemplo de lo anterior, en el camino que siguen las almas a Chametla, el lugar de los muertos, cada comunidad tiene su propia ruta en la que se encuentran distintos lugares ancestrales antes de llegar a Sihuacora, donde se unen los caminos de todos los pueblos del margen oriental del río Mezquital en dirección a la costa (Reyes Valdez et al. 2015, 113) ${ }^{21}$ Y si bien los comuneros de Santa María de Ocotán podrían reconocer el carácter ancestral de los sitios que se encuentran en la ruta desde Santiago Teneraca, no es un camino que sigan las almas de sus difuntos (idem). De forma muy destacada se encuentra también el reconocimiento que todos los tepehuanos tienen por Real de Catorce en el desierto potosino y que, por otra parte,

${ }^{20}$ Ello no significa la ausencia de relaciones de parentesco entre comunidades distintas. No obstante, en esos casos hay una primacía patrilocal.

${ }^{21}$ Éste es un detalle en el que Rangel Guzmán no repara $(2008 ; 2012)$, toda vez que su punto de referencia en la Ruta de los Muertos es la cabecera comunal de San Francisco de Ocotán. 
es uno de los lugares más importantes en el cosmograma huichol. Los tepehuanos reconocen ahí un lugar ancestral de suma importancia. No obstante, hay diversas historias de cómo debieron abandonar las peregrinaciones a dicho sitio y, en cambio, depositar las ofrendas respectivas en lugares ya cercanos o ya dentro de sus comunidades.

Los cerros patronales de los cuales hablé en el apartado anterior son los mejores y más claros puntos de referencia. Además de corresponder con los lugares de aparición de los santos patrones, son lugares de culto centrales para las comunidades y los grupos de parentesco. Por ejemplo, en Santa María de Ocotán, el Naksir tam, Cerro del Alacrán, es el depositario de la mayoría de las ofrendas entregadas a los jefes ceremoniales durante los mitotes. En una de las capillas que se encuentran en la cima, se depositan las varas y flechas emplumadas que personifican tanto a las deidades tutelares del centro ceremonial como a las plegarias de los individuos que participan en la ceremonia (Reyes Valdez 2006a, 113, 151-154). Este sitio también es el depositario de muchas de las flechas votivas de los curanderos y sus pacientes (Reyes Valdez 2010, 278).

Es muy importante reparar en que estos lugares xidhuukam forman conjuntos y se encuentran en relación con otros sitios de naturaleza semejante. El Naksir tam, por ejemplo, debe entenderse, por lo menos, con relación al patio ceremonial de mitote, con la iglesia del pueblo-cabecera de Santa María de Ocotán y con Susban tam, "el lugar del sapo", localizado en las inmediaciones del poblado Los Charcos. $^{22}$

Otro ejemplo que vale la pena destacar para ilustrar este punto, es el del cerro patronal en Santiago Teneraca, llamado Chianarak tam, lugar al que se atribuye la aparición de Santo Santiago. Éste forma un conjunto con otros trece lugares, algunos de ellos elevaciones, un patio ceremonial y un paraje sobre una piedra a la orilla del arroyo en donde se machacan las pencas de mezcal para la elaboración de una bebida fermentada que se consume durante el mitote del mes de enero. Éstos son los lugares:

${ }^{22}$ Lugar en donde se encuentra petrificado el sapo al que se atribuye haber traído las lluvias durante el primer mitote (Reyes Valdez 2006a, 240). 
1. Toto ai (Lugar a la orilla del arroyo)

2. Mobatak (Patio ceremonial cuya deidad tutelar es homónima al sitio)

3. Chianarak tam (Cerro Santiago)

4. Gasikar Tam (Cerro del Peine)

5. Tutuu kuapicha' (Peńasco Prieto)

6. Garabat tam (Cerro Garabato)

7. Bonaam tam (Cerro del Sombrero)

8. Timaich cha'm (Cerro Tamal)

9. Samidhal Cha'm (Cerro de la Espina)

10. Xixik tam (Cerro Aguililla)

11. Siñoligam tam (El Remolino)

12. Kakoon tam (Cerro El Cuervo)

13. Kukpara tam (Las Puertas, cerro que limita Santiago Teneraca al poniente)

14. Siram (Pico junto al Cerro Banco)

Durante una ceremonia de las lluvias celebrada en el mes de enero en uno de los patios de mitote de Santiago Teneraca, tres hombres entonan un canto acompañados con una sonaja de bule y mencionando todos estos lugares en ese orden. Se trata de un "recorrido oral" por todos estos lugares ancestrales que proveen el agua y la buena salud para los habitantes de la comunidad y del mundo. ${ }^{23}$

Un caso destacado, toda vez que cumple con los atributos de tener una importancia tanto en un nivel regional, como en uno local, es el Cerro Gordo. Llamado GÆ’kuta’m en lengua o’dam, es la máxima elevación de la Sierra Madre Occidental (3,340 msnm) y un punto en el que confluyen los límites de las comunidades de San Francisco de Lajas, San Bernardino de Milpillas y Santa María Mag-

${ }^{23}$ Hay múltiples ejemplos de lugares ancestrales que forman conjuntos entre los tepehuanos y en todo el Gran Nayar. Durante el mitote, los jefes ceremoniales en San Francisco de Ocotán depositan ofrendas en "doce cerros" correspondientes con doce ancestros y que se encuentran en las inmediaciones del centro ceremonial (Reyes Valdez 2006a, 83). Sin duda, el ejemplo más emblemático es la peregrinación de los huicholes a Reu'unaxi (Cerro Quemado en San Luis Potosí), la cual forma conjunto con las peregrinaciones a Hauxa Manaka (Cerro Gordo), Tatei Haramara (en la costa de Nayarit) y Xapawiyeme (en la Isla de los Alacranes, Jalisco) (Jáuregui et al. 2003). 
dalena Taxicaringa. La mitología tepehuana consigna que fue aquí donde el héroe cultural Jix Kai'Chiơn ñ combatió y venció a la Mujer Hielo (Benítez 1980, 140). Allende las comunidades tepehuanas, su importancia trasciende a otros pueblos del Gran Nayar, ya que corresponde con el punto norte de la cosmovisión huichola (Jáuregui et al. 2003), donde se cuenta encalló la canoa de Watakame el primer cultivador y su perrita después del diluvio (Medina Miranda 2012, 24-30).

En el nivel local, se trata del lugar de culto más importante para los "milpilleros", habitantes de la comunidad tepehuana de San Bernardino de Milpillas Chico, donde realizan rituales propiciatorios de lluvia y piden a las deidades por su vida y buena salud (Cramaussel 2014). De acuerdo con la información registrada por Cramaussel (2014, 140), lo que los milpilleros o mualhakam (habitantes de Mua'lham) denominan como "la ida al Cerro Gordo" corresponde con la visita que los habitantes de Santa María de Ocotán realizan al Naksir tam o Cerro del Alacrán al finalizar las ceremonias de mitote: "el objetivo de la peregrinación de los tepehuanos al Cerro Gordo es en primer lugar pedir por el agua, que no lleguen las langostas cuando el invierno fue demasiado templado, que no haya viento ni caiga granizo" (Cramaussel 2010, 45). Al igual que en los ejemplos anteriores, el Cerro Gordo denota un territorio para los milpilleros en conjunto con otras elevaciones como el Cerro San Miguel, La Cumbre, El Guajolote, Picudos y El Nopal (Cramaussel 2014, 145).

\section{El CARÁCTER TRANSFORMATIVO DEL TERRITORIO}

En mayo de 2015, la oficina estatal en Durango de la CDI extendió una invitación a las autoridades de Santa María de Ocotán para enviar una delegación que visitara, reconociera y entregara ofrendas en "lugares sagrados" en el desierto de Real de Catorce en el estado de San Luis Potosí. Lo anterior aún en el contexto del movimiento en defensa de Wirikuta promovido por las comunidades huicholas y diversas organizaciones de la sociedad civil, nacionales e internacionales, en contra de las concesiones para la explotación minera otorgadas por el gobierno federal. 
No cabe duda de que Real de Catorce es un lugar importante en la cosmovisión y la mitología de los tepehuanos, así lo confirman su mitología y los curanderos que con frecuencia lo mencionan en sus oraciones. No obstante, hasta donde alcanzan los registros etnográficos, las peregrinaciones multitudinarias y organizadas comunalmente no forman parte de sus tradiciones ceremoniales. ${ }^{24}$ De cualquier forma, después de varias discusiones acaloradas por lo que dicha invitación podría implicar, ${ }^{25}$ los comuneros de Santa María de Ocotán aceptaron la invitación.

En esta situación, los tepehuanos y los representantes estatales de la CDI llegaron a un acuerdo, si bien con sus respectivas agendas en mente. Sin embargo, dicho acuerdo refleja una característica de los tepehuanos en su relación para con sus lugares ancestrales, pero que contraviene la definición institucional de "lugares sagrados" citada líneas arriba y que resulta muy rígida en comparación con la noción indígena. Me refiero al "carácter transformativo" y cambiante del territorio y de los lugares ancestrales. El territorio está conformado por "un conjunto de lugares, socialmente producidos, que muta a medida que los actores se mueven en él" (Liffman 2012, 23). Los lugares ancestrales son antiguos por definición, "pertenecen a los ancestros", en consecuencia, se podría asumir que son bien conocidos. Sin embargo, esto no significa que sea un saber generalizado y mucho menos inamovible. Los dioses revelan frecuentemente "nuevos lugares ancestrales" que los humanos deben descubrir o redescubrir, mientras que otros son olvidados en un proceso permanente de reconstitución y resignificación del territorio. ${ }^{26}$ Por otra parte, y como expliqué líneas arriba, muchos de estos lugares sólo son significativos para ciertas comunidades y para ciertos grupos de

${ }^{24}$ Cabe enfatizar que me refiero aquí a un culto organizado comunitariamente, ya que hay tepehuanos que, por iniciativa propia, de manera individual y reconociendo el valor ancestral de Real de Catorce, rinden culto o adquieren compromisos ceremoniales en el lugar.

${ }^{25}$ Entablar una relación con los lugares ancestrales significa establecer una relación con los ancestros de dicho lugar, e implica una serie de obligaciones ceremoniales so pena de enfermedad, desgracia o muerte.

${ }^{26}$ Siguiendo a Ingold $(2011,172)$ "los ambientes nunca están completos, sino que se encuentran bajo una continua construcción”. 
parentesco, por lo cual sólo pueden ser identificados por sus miembros. Lo anterior para los propios miembros de las comunidades tepehuanas complica establecer de manera concreta y finita esas listas o catálogos de lugares sagrados muchas veces demandadas por las instituciones.

Por lo que respecta al culto de los tepehuanos en Real de Catorce, vale la pena señalar que, según la tradición oral, es uno de aquellos sitios de culto que en algún momento fue abandonado por las comunidades. Por lo menos en Santiago Teneraca aseguran que uno de sus patios ceremoniales enviaba hacia allá las flechas rituales al finalizar los mitotes. No obstante, sus jefes decidieron en algún momento y con base en muchos sacrificios rituales, cambiar el destino de dichos objetos para depositarlos en un "nuevo lugar ancestral" en las inmediaciones de la comunidad. ${ }^{27}$

La decisión de aceptar la invitación de la CDI no fue fácil, y fue objeto de largas discusiones entre las autoridades comunales. Los curanderos y muchos ancianos de Santa María de Ocotán tuvieron que considerar no sólo todas las abstinencias ceremoniales a las que deberían someterse de manera estricta los participantes, obligaciones que tendrían que cumplirse durante por lo menos cinco años, involucrando una cantidad substancial de dinero y trabajo ritual. Hoy en día todavía es muy pronto para saber y comprender los efectos duraderos del nuevo reconocimiento de este lugar ancestral.

\section{Conclusiones}

Una revisión de la historia y la etnografía reciente de los tepehuanos del sur de Durango nos muestra un solo y gran tema que motiva una relación de confrontación explícita con el Estado mexicano: el pleno control de sus tierras y la autonomía política de sus comunidades. Aunado a lo anterior, el reciente boom del interés por los lla-

${ }^{27}$ En Santa María de Ocotán cuentan una historia muy similar pero en relación con un lugar cercano al pueblo cora de La Mesa del Nayar llamado El Cangrejo, donde antiguamente se depositaban algunos objetos ceremoniales del mitote que hoy en día se dejan en la cima del Naksir tam (Reyes 2006a, 191). 
mados "lugares sagrados", por parte de diferentes agentes externos a las comunidades, especialmente diversas instancias del Estado mexicano, ha motivado un nuevo punto de discusión en torno al territorio. Como he mostrado a lo largo del texto, este desencuentro deriva en gran medida de dos concepciones distintas del territorio y de dos presupuestos diferentes de aquello que podría denominarse como "lugares sagrados".

De manera práctica, estas diferencias redundan en la incomprensión mutua y malentendidos entre las comunidades tepehuanas y los representantes de diversas agencias estatales. Por ejemplo, en años recientes, durante la redacción de los Estatutos Comunales de Santa María de Ocotán y Xoconoxtle, tanto personal representante de la CDI y algunas personas de la comunidad, expresaron su frustración ante el hecho de que, por un lado, los primeros no lograban obtener información por parte de los comuneros y, los segundos, no entendían de qué les estaban hablando, lo que resultó en la apariencia de que no había lugares sagrados susceptibles de registrarse ni ser potencialmente protegidos. Quizás, por esta razón, la propuesta de Estatutos Comunales para esta comunidad sólo menciona la iglesia de la cabecera comunal, el patio comunal del xiotalh y un patio de xiotalh familiar correspondiente con el grupo de parentesco del gobernador tradicional en turno.

En ese contexto, Carolina Mendoza (comunicación personal), directora de la Radiodifusora Cultural Indigenista con sede en Santa María de Ocotán, me comentó, en un par de entrevistas que mantuvimos en 2015, que con frecuencia las oficinas regionales de la CDI en Durango y centrales en la Ciudad de México le solicitaban generar contenidos sobre "los lugares sagrados". Sin embargo, no era algo que la gente de la localidad tuviera conocimiento o hablara al respecto, lo que a funcionarios de la radio llevaba a una de tres conclusiones: a) los tepehuanos no tienen o tienen muy pocos lugares sagrados; b) los tepehuanos en general son ignorantes acerca de los lugares sagrados y es necesario dar con los especialistas; o c) los tepehuanos son "cerrados" para hablar de sus lugares sagrados.

Como expliqué a lo largo del texto, las cualidades que podrían postularse como "sagradas" entre los tepehuanos derivan del carác- 
ter "ancestral" de los objetos, personas o lugares que tienen dicho atributo y que en o'dam se puede identificar bajo la cualidad de xidhuukam (Reyes Valdez 2015, 59). Por lo que respecta al espacio, todo el territorio tepehuano tiene la calidad de ancestral dado que fue creado y habitado por los ancestros. En consecuencia y extrapolando la noción de xidhuukam con la de sagrado, es posible afirmar que "todo el territorio es sagrado" para los tepehuanos.

A fuerza de encontrar coincidencias entre las nociones tepehuana y de las instituciones gubernamentales, es necesario resaltar que hay un tipo de lugares que sí corresponde en gran medida con ambas nociones: aquellos lugares que se conciben como la morada de los ancestros o como testigos de eventos acontecidos en tiempos ancestrales. En ese caso, la principal dificultad para una identificación exhaustiva, como se espera en algunos peritajes, resulta de su gran número; pero, sobre todo, de que no todos estos sitios son de dominio público. Muchos lugares ancestrales sólo tienen importancia y por tanto sólo son de conocimiento para determinados grupos de parentesco. Finalmente, resultaría en un error simplemente sustituir el término "lugar sagrado" por el de "lugar xidhuukam", pues, ello negaría además el "carácter transformativo" de dichos sitios y la posibilidad del descubrimiento de nuevos lugares ancestrales.

\section{BiBLIOGRAFÍA}

Alvarado Solís, Neyra Patricia. 2004. Titailpi...timokotonal. Atar la vida, trozar la muerte. El sistema ritual de los mexicaneros de Durango. México: Universidad Michoacana de San Nicolás de Hidalgo, Exconvento de Tiripetío.

Ambriz, María y Eliseo Gurrola. 2013. Mui'sapok. Relatos de la tradición oral de los tepehuanos del sur. Vol. I. México: Instituto Nacional de Antropología e Historia.

Benítez, Fernando. 1980. Los indios de México. Vol. V. Tepehuanes y nahuas. México: Era.

Brotherston, Gordon. 1992. Book of the Fourth World. Nueva York: Cambridge University Press.

Calvillo, Guillermo. 2004. "Ethnographie du Conflit Des Tepe- 
huanes du Sud: L'Espace de la Memoire”. M: A. Anthropology, París: Ecole des Hautes Etudes en Sciences Sociales.

Comisión Nacional de los Derechos Humanos (CNDH). 2015. Sitios sagrados y derechos humanos de los pueblos indígenas. MéxiCO: CNDH.

Comisión Nacional Para El Desarrollo De los Pueblos InDÍGENAS (CDI). 2010. Informe final de la Consulta sobre lugares sagrados del pueblo Wixarika. México: CDI.

Coyle, Philip E. 2001. Náyari History, Politics, and Violence. From Flowers to Ash. Tucson: The University of Arizona Press.

Cramaussel, Chantal. 2010. "Mulhuam o San Bernardino de Milpillas Chico, Dgo. El pueblo de la Sierra Tepehuana donde se sembraba agua del mar". Revista de Historia (2): 22-50.

2014. "El recorrido al Cerro Gordo y el ritual tepehuano de las ofrendas en los cerros de la comunidad de San Bernardino de Milpillas". Frontera Norte 26(52): 135-54.

Cruz, Sixto de la. 2007. "Gu Chiop”. En Mamtuxiñndham ja'sapok Boodamtam kam Korian, ed. Santos Galindo Mendoza, 43-49. México: Instituto Nacional de Lenguas Indígenas.

Descola, Philippe. 2012. Más allá de naturaleza y cultura. Buenos Aires-Madrid: Amorrortu.

ERIKSON, Philippe. 1986. "Altérité, tatouage et anthropophagie chez les Pano: la belliqueuse quête du soi". Journal de la Société des Américanistes (72): 185-210.

Hobgood, John. 1970. "The Ixcaitiung or Ruling Man and the Chul. A Tepehuan Epic”. Internationalen Amerikanistenkongresses (2): 33-52.

Ingold, Tim. 2011. Being Alive. Essays on Movement, Knowledge and Description. Londres y Nueva York: Routledge.

Jáuregui, Jesús y Laura MAGRIÑá. 2002. "Estudio etnohistórico acerca del origen de los mexicaneros (hablantes de náhuatl) de la sierra Madre Occidental”. Dimensión Antropológica, año 9(26): 27-81.

Jáuregui, Jesús, Paulina Alcocer, Philip Edward Coyle, Adriana Guzmán, Johannes Neurath, Laura Magriñá y Margarita VAldovinos. 2003. "La autoridad de los antepasados. ¿Un siste- 
ma de organización social de tradición aborigen entre los coras y huicholes?" En La comunidad sin limites. Estructura social y organización comunitaria en las regiones indígenas de México, Vol. 3. Serie Etnografía de las regiones indígenas de México, ed. Saúl Millán y Julieta Valle. México: Instituto Nacional de Antropología e Historia.

LiffMAn, Paul M. 2012. La territorialidad wixarika y el espacio nacional. Reivindicación indígena en el occidente de México. México: El Colegio de Michoacán, Ciesas.

2015. "Cosmopolitics and Media in the Wixarika AntiMining Movement”. Ponencia presentada en 114a Annual Meeting of the American Anthropological Association, Denver, Colorado, noviembre 20.

López BÁrCENAS, Francisco. 2015. jLa tierra no se vende! Las tierras y los territorios de los pueblos indígenas de México. México: Centro de Orientación y Asesoría a Pueblos Indígenas.

Lumholtz, Carl. 1986 [1902]. El México desconocido. Cinco años de exploración entre las tribus de la Sierra Madre Occidental; en la Tierra Caliente de Tepic y Jalisco, y entre los tarascos de Michoacán. Vol. I. Nueva York: Charles Scribner's Sons.

Maldonado, Saúl. 2015. "Siguen indígenas en la Sagarpa”. El Siglo de Durango. Sección Regional. 9 de enero de 2015.

Martínez Guzmán, Gabino. 2004. Bernalejo. Historia de una infamia. Durango: Universidad Juárez del Estado de Durango.

Medina Miranda, Héctor M. 2012. Relatos de los caminos ancestrales. Mitología wixarika del sur de Durango. México: Universidad Autónoma de San Luis Potosí, Miguel Ângel Porrúa.

Mendía Soto, Honorio. 2016. "La justicia oral y comunal: el caso de los tepehuanos del sur (Santa María de Ocotán y Xoconoxtle, Durango)". Tesis de Maestría en Estudios Antropológicos en Sociedades Contemporáneas, Universidad Autónoma de Querétaro. Morris, Nathaniel. 2015. "The World Created Anew: Land, Religion and Revolution in the Gran Nayar Region of Mexico". Doctorado en Historia, University of Oxford.

Moszowski Van Loon, Aäron, Antonio Reyes y Honorio MenDíA. 2018. "La explotación forestal en las comunidades indíge- 
nas del sur de Durango: Un alegato a favor de un pluralismo ontológico genuino". En Procesos socioambientales en las regiones indígenas de México. Serie Etnografía de las regiones indígenas de México, ed. Aida Castilleja y Javier Gutiérrez. México: Instituto Nacional de Antropología e Historia (en prensa).

Neurath, Johannes. 2008. "Alteridad constituyente y relaciones de tránsito en el ritual huichol: iniciación, anti-iniciación y alianza”. Revista Cuicuilco 15(42): 29-44.

. 2015. "Wixarika Cosmopolitics and Ecology". Ponencia presentada en 114a Annual Meeting of the American Anthropological Association, Denver, Colorado, noviembre 20.

Pitarch, Pedro. 2000. "Conjeturas sobre la identidad de los santos tzeltales”. Journal de la Société des Américanistes (86): 129-148.

Quiñones Martínez, Cynthia Teresa. 2013. "Las leyes de tierras de 1856 a 1909 y su impacto en la propiedad territorial en Durango". En Historia de Durango, Siglo XIX. Tomo III, ed. Gloria Estela Cano Cooley, 222-271. México: Instituto de Investigaciones Históricas-Universidad Juárez del Estado de Durango.

Rangel GuzMán, Efraín. 2008. "El mito del camino de los muertos en la cosmovisión tepehuana”. Revista Transición (36): 38-63.

2012. Imágenes e imaginarios. Construcción de la región cultual de Nuestra Señora de Huajicori. México: Universidad Autónoma de Ciudad Juárez, El Colegio de Michoacán.

Reyes Valdez, Antonio. 2006a. Los que están benditos. El mitote comunal de los tepehuanes de Santa María de Ocotán. Etnografía de los Pueblos Indígenas de México. México: Instituto Nacional de Antropología e Historia.

. 2006b. Tepehuanes del sur. Pueblos indígenas del México contemporáneo. México: Comisión Nacional para el Desarrollo de los Pueblos Indígenas.

. 2009. Formas de gobierno y autoridades indígenas: el caso de los tepehuanos del sur. Antropología Social 99. México: Comisión Nacional para el Desarrollo de los Pueblos Indígenas.

. 2010. "Cazadores de almas. Las flechas tepehuanas y el arte de la personificación”. En Las artes del ritual. Nuevas aportaciones para la antropología del arte desde el occidente de México, ed. 
Elizabeth Araiza, 267-295. México: El Colegio de Michoacán. . 2013. "Los pueblos indígenas de Durango en el siglo XxI". En Historia de Durango, Siglo XX. Tomo IV, ed. Mauricio Yen, 372-408. México: Instituto de Investigaciones Históricas-Universidad Juárez del Estado de Durango.

. 2015. "The Perpetual Return of the Ancestors. An Ethnographic Account of the Southern Tepehuan of Mexico and their Deities". Tesis de Doctorado en Antropología Social, University of St Andrews.

2018. "Ja'ook, el viejo de la danza de Durango". Artes de México (marzo).

Reyes Valdez, Antonio, Andrés Oseguera Montiel, Ricardo Claudio Pacheco Bribiesca y Eduardo R. Saucedo SÁnchez DE TAGLE. 2015. "De la ambivalencia al tabú. Las transformaciones del concepto de persona en el noroeste de México". En Creando mundos, entrelazando realidades. Cosmovisiones y mitologías en el México indigena. Vol. II, ed. Catherine Good y Marina Alonso Bolaños, 97-174. México: Conaculta, Instituto Nacional de Antropología e Historia.

Reyes Valdez, Antonio y Gabriela García Salido. 2017. “Los topónimos o'dam. Vida social y memoria de un pueblo del noroeste de mexicano". En La memoria de los nombres: la toponimia en la conformación histórica del territorio. De mesoamérica a México, ed. Karine Lefebvfe y Carlos Paredes Martínez, 335-62. México: Centro de Investigaciones en Geografía Ambiental-Universidad Nacional Autónoma de México.

Riley, Carroll L. y John Hoвgood. 1959. "A Recent Nativistic Movement among the Southern Tepehuan Indians". Southwestern Journal of Anthropology 15(4): 355-360.

Rosa, Aciano de la. 2003. Historia de la politica y de la justicia del tepehuano del Mezquital, Durango. Antropología Social 92. México: Comisión Nacional para el Desarrollo de los Pueblos Indígenas.

Ruiz Medrano, Ethelia. 2010. Mexico's Indigenus Communities. Their Lands and Histories, 1500. Mesoamerican Worlds. Boulder: University Press of Colorado. 
SÁnchez Olmedo, José. 1980. Etnografía de la Sierra Madre Occidental. Tepehuanes y mexicaneros. Colección Científica 92. México: Instituto Nacional de Antropología e Historia.

Sandoval, Zazil, René Esparza, Teresa Rojas Rabiela y Regina Olmedo. 1999. Las tierras comunales en México. México: Ciesas, Registro Agrario Nacional.

Sото Soто, Onésimo. 2015. "La explotación forestal en Santa María de Ocotán y Xoconoxtle en el siglo xx". Revista de Historia de la Universidad Juárez del Estado de Durango (7) (enero-diciembre): 139-160.

VAldovinos, Margarita. 2008. "Les chants de mitote náyeri. Une pratique discursive au sein de l'action rituelle". Tesis de grado en Etnología, Universidad de París X.

Valiñas, Leopoldo. 1991. "Los mexicaneros de Durango no son de Tlaxcala, memorias, 1988". En Primeras Jornadas de Etnohistoria. Memorias. Cuadernos de Trabajo 10, ed. María del Refugio Cabrera Vargas y Nelida Bonaccorec, 339-351. México: Escuela Nacional de Antropología e Historia.

Viveiros de Castro, Eduardo. 2013. "Perspectivismo y multinaturalismo en la América Indígena”. En Cosmopolíticas. Perspectivas antropológicas, ed. Montserrat Cañedo Rodríguez, 417-456. Editorial Trotta.

Willett, Thomas L. 1991. A Reference Grammar of the Southeastern Tepehuan. Dallas: Summer Institute of Linguistics. 